\title{
The Impact of Cooperative Structure and Firm Culture on Market Orientation and Performance
}

\author{
Kyriakos Kyriakopoulos \\ University of Maastricht, Department of Marketing, P.O. Box 616, \\ 6200 MD Maastricht, The Netherlands. \\ E-mail: k.kyriakopoulos@mw.unimaas.nl \\ Matthew Meulenberg \\ Wageningen University, Department of Marketing and Marketing Research, \\ Hollandseweg 1, 6706 KN, Wageningen, The Netherlands. \\ E-mail: Thieu.Meulenberg@wur.nl \\ Jerker Nilsson \\ Swedish University of Agricultural Science, Department of Economics, \\ P.O. Box 7013, S-75007, Uppsala, Sweden. \\ E-mail: jerker.nilsson@ekon.slu.se
}

\begin{abstract}
Building on recent advances in cooperative literature and practice, we conceive two key organizational features of cooperatives: cooperative structure (in terms of control, ownership, and cost/ pricing policies resulting in traditional and re-engineered co-ops) as well as entrepreneurial cooperative firm culture. Then we conceptualize and test the effect of these organizational features on the market orientation and performance of the cooperative firm relying on a sample of Dutch co-ops. We cannot establish a systematic influence of the cooperative structure; however, a significant influence of individualized member ownership on performance and of cost/pricing policies on market orientation has been found. Entrepreneurial firm culture has a significant effect on both market orientation and performance. [EconLit citations: L200, M310, Q130.] (C) 2004 Wiley Periodicals, Inc.
\end{abstract}

\section{INTRODUCTION}

The structure and the performance of cooperatives are key issues in the literature. While the neoclassical approach (i.e., Helmberger \& Hoos, 1995; Nourse, 1945) suggests that co-ops can be formidable competitors to IOFs (investor-owned firms), other research building on agency and game theory suggests that co-ops' traditional principles undermine optimal resources allocation and investment policies (Vitaliano, 1983) as well as the stability of coalitions of various groups in the cooperative (Sexton, 1986; Staatz, 1983).

In an effort to reconcile these conflicting perspectives, a growing research stream proposes a variety of cooperatives models (Barton, 1989; Cook, 1995, 1997; Kyriakopoulos, 
2000; Nilsson, 1998; Van Dijk, Kyriakopoulos, \& Nilsson, 1997), capturing the emergence of a new model for cooperatives variously called new generation, re-engineered, or proportional co-ops. In addition to changes in cooperative structure, cooperative firms are reorganized to bolster an entrepreneurial and innovative management and culture (Cook, 1995; Kyriakopoulos, 2000). Changes in cooperative structure and culture are suggested to facilitate market-oriented strategies (Meulenberg, 1996) as a response to increasing and global competition and changing customer preferences.

Positioned in the cooperative models research stream, this study seeks to shed light on the impact of two key cooperative organizational features-cooperative structure and cooperative firm culture-on the market orientation and performance of cooperative firms by addressing the following gaps associated with cooperative research. First, while re-engineered cooperatives have been discussed extensively, they have not been clearly distinguished from traditional cooperatives by unambiguous and measurable variables. In this study we differentiate these two classes of cooperatives, traditional and re-engineered on the basis of specific structural factors related to the three basic principles of cooperative structure, user-owned, user-controlled and user-benefit. Second, features of the cooperative firm, such as entrepreneurial culture and leadership, though they are suggested to explain firm success, in general, (e.g., Deshpandé, Farley, \& Webster, 1993; Moorman, 1995), have been overlooked in the cooperative studies. Third, our study also seeks to extend prior empirical research on the performance of cooperatives by introducing market orientation, which is a familiar concept in the business science literature (e.g., Deshpandé, 1999; Porter, 1980), as an outcome variable of cooperative structure and culture. Studies of cooperative performance in the past have relied on a limited number of financial indicators, such as balance sheet ratios (e.g., Gentzoglanis, 1997; Hind, 1994; Lerman \& Parliament, 1990). However, in this study we introduce an overall evaluation of cooperative performance as proposed by Deshpandé et al. (1993).

To address these gaps, we have organized the paper as follows. First, we describe two organizational features of cooperatives: cooperative structure as well as entrepreneurial cooperative firm culture. Second, we conceptualize the effect of these organizational features on the market orientation and performance of the cooperative firm. Then, we report the data collection and analysis as well as the results of the empirical investigation among Dutch co-ops. We conclude this paper with the implications of the findings and the study limitations.

\section{TWO ORGANIZATIONAL FEATURES OF COOPERATIVES: STRUCTURE AND FIRM CULTURE}

In this section we describe the two key organizational features of cooperatives. We begin with the cooperative structure and, specifically, elaborating the three principles linking the members to their cooperative association. Then, we introduce the entrepreneurial culture as a feature of a cooperative firm.

\subsection{Cooperative Structure}

Building on three definitional principles of cooperative structure-user-owner, usercontrol, and user-benefit (Cook, 1995) — and drawing from cooperative experience in practice, we define specific structural factors in relation to each principle. 
2.1.1 Ownership. Cooperatives address the following issues concerning ownership (Cobia \& Brewer, 1989): (a) who can own/contribute to cooperative equity; (b) how is cooperative equity allocated; (c) how do cooperatives redeem equity; (d) how is the cooperative's net income allocated? First, cooperatives have historically adhered to exclusive member ownership of their equity. Member ownership is in the unique form of direct investment, retained patronage refunds, per-unit capital retains ${ }^{1}$ (Cobia \& Brewer, 1989), and recently in the form of long-term loans or bonds with fixed return issued to members (van Dijk et al., 1997). Over the last decades, very few cooperatives have relaxed this exclusive member-ownership principle ${ }^{2}$ in inviting nonmember parties to partially finance their operations (van Dijk et al., 1997).

As far as the allocation of cooperative equity is concerned, while cooperatives have typically sizable unallocated reserves (originating from retained member patronage refunds), an increasing number of co-ops has individualized their reserves in proportion to members' patronage (i.e., members' accounts or individually held shares). Third and related, co-ops differ in equity redemption. ${ }^{3}$ In traditional cooperatives, members are redeemed only the nominal value of the membership certificates (of limited value) upon exit. In contrast, when equity is individualized, members can capture benefits (or losses) due to changes in firm equity in two alternative ways: individual member accounts receive equity gains regularly (e.g., redemption plans, retained patronage dividends) or members capture directly the gains by trading their shares (e.g., the Dutch dairy co-op FCDF has established an internal secondary market for member shares). Finally, the distribution of net income ${ }^{4}$ can occur through a price adjustment (patronage refunds paid to the users after the financial year has been concluded) or through a combination of a dividend on members' invested capital in proportion to their patronage and an average market price.

2.1.2 Control. Control in cooperatives, essentially, boils down to the following questions (Ginder \& Deiter, 1989): (a) who is allowed to vote; (b) what is the voting rule? In contrast with IOFs, traditionally co-ops allow only their members to vote on fundamental cooperative decisions such as electing the members of Farmers' Board, approval of annual reports, acquisition of new business, etc. to ensure that members have the control. However, some cooperatives have allowed that nonmembers with voting rights in the Farmers' Board could be external equity holders. Regarding the voting rights allocation, inspired by Rochdale, Raiffeisen and other pioneers, cooperatives have largely adopted democratic control (i.e., one-member one-vote principle; Barton, 1989). Gradually, some co-

\footnotetext{
${ }^{1}$ Direct investment refers to the start-up capital in the form of membership certificates or shares in proportion of patronage. Retained patronage refunds, popular among American co-ops, are portions of net income retained by the cooperative. Per-unit capital retains are members investments according to the number or value of units handled for each member. For a detailed account of cooperative financing, see Cobia and Brewer (1989).

${ }^{2}$ According to the definition followed here, a co-op, in which nonmembers have the majority of equity ownership, can be no longer regarded as a cooperative. This is mainly true in many Irish cooperatives although one can find examples in other countries, too (Harte, 1997).

${ }^{3}$ It refers not only to member equity but also asset appreciation according to the performance of cooperative.

${ }^{4}$ Although net income distribution partly relates to the user-benefit principle, it is tied to the ownership structure of the cooperative and thus we treat it under the heading user-owner principle. Although net income is calculated by subtracting costs from income, is should not be confused with net profit, a term used for IOFs. Cooperative net income is not equivalent to taxable income and it embraces price adjustments. These price adjustments are called patronage refunds in the form of premiums and discounts for marketing and supply cooperatives paid in the end of the year to supplement the advance payments paid after the transaction completed.
} 
operatives have replaced the one-member, one-vote principle with a proportionality principle, according to which, members' voting is roughly a function of their patronage.

2.1.3 The cost/pricing policy. In contrast with IOFs, cooperatives' pricing policy, i.e., setting prices to farmers for products marketed, supplies sold, and services provided, aims not at making profits but offering benefits to the members. Co-ops ideally, though not always in reality, function to offer the highest prices for raw material marketed (marketing co-ops), and charge the lowest prices for supplies (supply co-ops), which are affordable in view of the market situation and operational costs. Building on this unique feature of their marketing policy, cooperatives differ in the per-unit pricing of raw material handled. This ranges from uniform or equal pricing to differential or equitable pricing. Equal pricing, the same or similar prices/cost charged, reflects the average cost of handling the raw material. Differential pricing involves premiums and discounts to members depending on location, volumes, or quality to reflect differences in marginal costs or marginal revenue.

2.1.4 Two cooperative models: Traditional vs. re-engineered. On the basis of differences in the fundamental cooperative principles of ownership, control, and costs/ pricing policies, cooperatives are classified in traditional versus re-engineered cooperative models. Table 1 describes the various structural factors in case of traditional and re-engineered cooperatives. Re-engineering of traditional cooperatives involves a limited participation of external parties in control and ownership and the application of proportionality in treating members. Most importantly, it involves voting rights and individualized equity according to the patronage as well as equitable pricing of co-op's services and products.

\subsection{Entrepreneurial Firm Culture}

Organizational arrangements in connecting members with their cooperatives are important to cooperative firms but attributes of the cooperative firm are also influential on

TABLE 1. Structural Factors and Cooperative Models

\begin{tabular}{lll}
\hline Structural factors & Traditional cooperatives & Re-engineered cooperatives \\
\hline $\begin{array}{l}\text { Control } \\
\text { Voting rights }\end{array}$ & Only members (50) & Minority of nonmembers (2) \\
Voting principle & Democratic control (21) & Proportional (31) \\
Ownership & Only members (48) & Nonmembers as minority (4) \\
Qualify for stocks & Collective (26) & Individualized, i.e., shares, (25) \\
Type of equity & Limited fees (24) & $\begin{array}{l}\text { Proportional (24) } \\
\text { Entry fees }\end{array}$ \\
Equity redemption & Nominal value (37) & $\begin{array}{c}\text { Tradeable shares or regular } \\
\text { redemption plans (14) }\end{array}$ \\
Net income allocation & Through prices (30) & Prices and personal shares (20) \\
Costs/Pricing policy & & \\
Pricing Policy & Equal (11) & Equitable (36) \\
Costs allocation & Volume neutral (19) & Volume-related (26) \\
\hline
\end{tabular}

Note. The number of co-ops in our sample exhibiting a certain feature is indicated in parentheses. 
market orientation and performance. Cooperative research, for example, suggests that growth-oriented professional management (Cook, 1994; Ginder \& Deiter, 1989;), nonhierarchical structure (Van Dijk \& Mackel, 1991), and innovative strategy and risk preference (Meulenberg, 1996) affect the market orientation and the performance of the cooperative firm. We follow in the tradition of an emerging body of literature (Deshpandé et al., 1993; Moorman, 1995; Quinn \& McGrath, 1984) to suggest that entrepreneurial culture - associated with the above-mentioned characteristics — is an "asset" that has the potential to capture these traits.

Entrepreneurial cultures ${ }^{5}$ - also referred to as adhocracies - are generally characterized by external orientation and organic structure (Cameron \& Freeman, 1991; Quinn \& McGrath, 1984). More specifically, entrepreneurial cultures display four key attributes: risk-taking attitude, innovative leadership style, flexible bonding mechanisms, and proactive strategic emphasis (Moorman, 1995). Cultures are cornerstones of the strategy and management of a firm. Specifically, an entrepreneurial culture affects the firm's choice of its goals (e.g., emphasis on efficiency vs. innovativeness) and the means to achieve these outcomes, including organizational strategies and processes (Cameron \& Freeman, 1991; Deshpandé et al., 1993; Moorman, 1995; Quinn, 1988; Quinn \& Rohrbaugh, 1983).

\section{CONCEPTUAL FRAMEWORK}

In this section we develop arguments about the effect of organizational features of cooperatives, as discussed in section 2, on the cooperative firm's outcomes-market orientation and performance. In the following sections, we introduce the outcomes and then the relationship between organizational features and outcomes in the form of hypotheses.

\subsection{Cooperative Firm Outcomes}

3.1.1 Market orientation. Marketing and management science have argued that superior customer value is instrumental in achieving a sustainable competitive advantage (e.g., Deshpandé, 1999; Porter, 1980). In the field of marketing, there are several, but converging, definitions of market orientation (Deshpandé, 1999; Jaworski \& Kohli, 1993; Narver \& Slater, 1990). We adopt the definition of Narver and Slater (1990) who argue that market orientation consists of (a) competitor orientation, which includes the activities involved in acquiring information about the competitors in the target market and transmitting it throughout the firm, (b) customer orientation, which includes the activities involved in acquiring information about the customers in the target market and disseminating it throughout the firm, and (c) inter-functional coordination, which comprises the firm's coordinated efforts, involving more than the marketing department, to create superior value for the customers. Empirical research has found strong evidence that market orientation is a key strategic predictor of a firm's long-term competitive position (e.g., Homburg \&

\footnotetext{
${ }^{5}$ Although there are different definitions of culture, we adopt the framework of competing values developed by Quinn and his colleagues (e.g., Quinn, 1988; Quinn \& Rohrbaugh, 1983; Quinn \& McGrath, 1984). Briefly, the model proposes two predominant dimensions by which cultural values vary. These two axes form a four-cell model of culture. One axis, the informal-formal dimension, reflects preferences about the importance of organizational structure and involves a continuum from organic to mechanistic processes. The second axis, the internal-external dimension, describes whether the emphasis is on the maintenance of an organization's internal sociotechnical system or the improvement of its competitive position within the external environment.
} 
Pflesser, 2000; Jaworski \& Kohli, 1993; Narver \& Slater, 1990), because it increases customer satisfaction, customer loyalty, and new product success.

3.1.2 Performance. Accounting performance measures, e.g., return on investment (ROI) or solvency, are hard to measure and interpret in the case of cooperatives, which aim at paying their members the best price for the products received, or to charge the lowest price for the products and services supplied. Though the measurement of a cooperative firm's performance is controversial, we will follow in the tradition of business sciences to measure it as a multidimensional construct (see Appendix) comprising market share, profit margin, and growth of the cooperative firm relative to main competitors in the market (Deshpandé et al., 1993). Our measure utilizes market indicators of firm performance (i.e., market share and relative market growth) and financial indicators measured at both market and cost level (i.e., profit margin), departing from accounting measures used in previous studies.

\subsection{Hypotheses}

We assume that market orientation and performance are influenced by the structural traits of cooperatives and by the cooperative firm culture (Fig. 1). Interdependent relationships between structure and outcomes, e.g., as a result of feedback from performance to ownership arrangements, cannot be excluded a priori. However, in our case the assumption of unilateral causal relationships seems valid since structural characteristics are basic cooperative variables, which change gradually only as compared to outcomes (e.g., performance is a volatile variable as a result of dynamic agricultural and food markets). This argument seems to hold a fortiori for potential interdependency between entrepreneurial

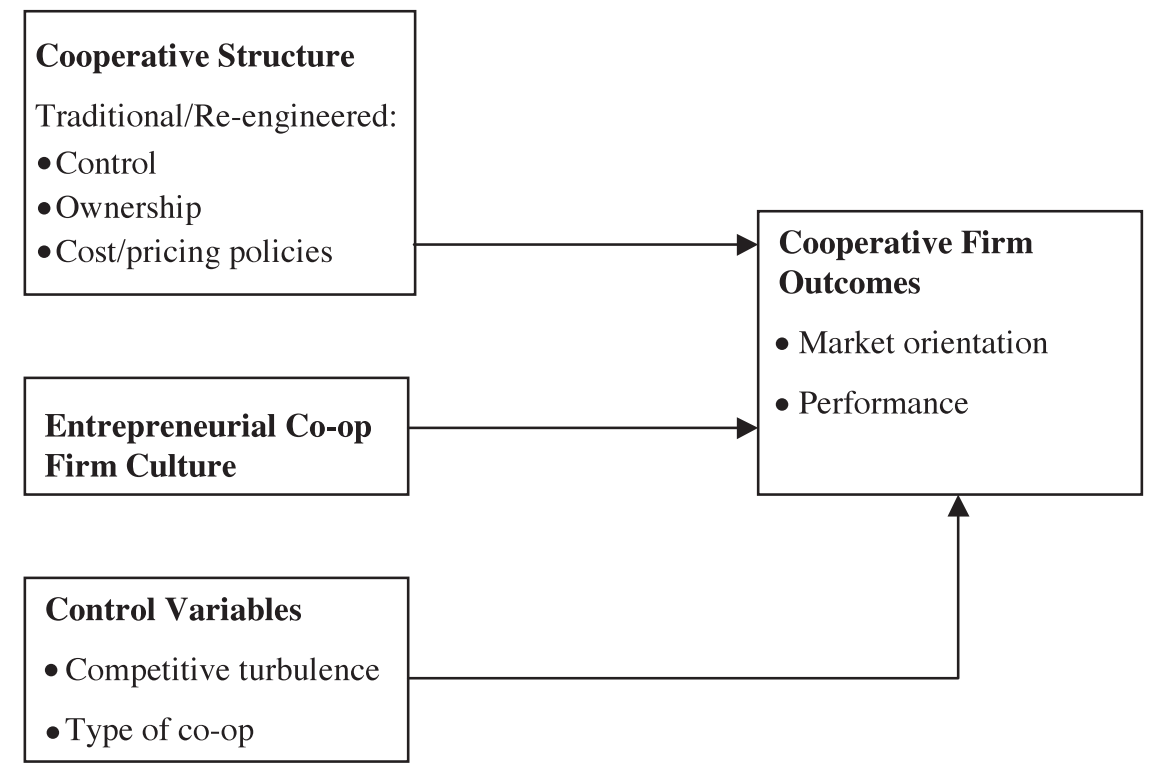

Figure 1 The effect of cooperative structural features, entrepreneurial co-op firm culture, and control variables on the market orientation and performance of the cooperative firm. 
culture and outcomes for a number of reasons. Entrepreneurial culture is a general, attitudinal firm characteristic (thus, enduring and long-term) that defines the context (e.g., norms, values, sanctions) for devising and executing market-oriented strategies, according to many studies (e.g., Homburg \& Pflesser, 2000; Moorman, 1995). In addition, entrepreneurial cultures do not necessarily lead to market orientation (Moorman, 1995). Finally, other environment (e.g., changing customer needs) or firm-related (e.g., top management support) factors (Jaworski \& Kohli, 1993) can drive market orientation.

In addition to the three cooperative variables and culture emanating from our research questions, our conceptual model includes a general structural cooperative variable, type of cooperative, specified as either a supply or a marketing cooperative. This difference is expected to influence cooperative market orientation and performance because of differences in type of product (means of production vs. consumer products), type of customer (enterprises vs. final consumers) and different role in the supply chain. Finally, competitive intensity has been included as an environmental variable of the cooperative, which might influence market orientation and performance: a turbulent market environment may increase the need for market orientation but weaken performance, such as profit margins (Narver \& Slater, 1990).

3.2.1 The effect of cooperative structure. Traditional control arrangements-the one-member one-vote principle and exclusive member voting rights-will reduce cooperative firms' market-orientation and performance for two key reasons. First, the onemember, one-vote rule is not attractive to large farms in conditions of increasing diversity of members in terms of size, entrepreneurship, risk behavior, and values (Hakelius, 1996; Staatz, 1984), because their impact on decision-making is disproportional to their patronage and financial contribution (Sexton \& Iskow, 1988).

Second, lack of external members in the Board of Directors, typically the case in small co-ops, could well bias marketing policies to activities close to farmers-members and not to the customer and other external parties (Staatz, 1984; Vitaliano, 1983) or lead to lengthy and time-consuming discussions (Hendrikse \& Veerman, 1997; Henehan \& Anderson, 1994). Finally, there will be a tendency to avoid exposure to risky, innovation intensive operations (Harte, 1997; Nilsson, 1998) or a tendency to avoid expansion to profitable stages of the food chain (Royer, 1995). Thus:

$\mathbf{H}_{1}$ : In comparison to re-engineered co-ops, control arrangements in traditional cooperatives will detract from (a) the market orientation and (b) the performance of the cooperative firm.

Traditional ownership arrangements-exclusive member and collective ownership, low or no entry fees, no dividend, not equity redemption-will hurt market orientation and performance. First, exclusive member ownership simply deprives a cooperative firm from the external financial resources to undertake investments in branding, new product development, product differentiation. Furthermore, no entry fees have another adverse effect: because a new member can immediately enjoy the advantage of accumulated assets to which he has not contributed, the cooperative property becomes a public good and the "free-rider" problem arises, leading to the common property problem (Nilsson, 1998; Vitaliano, 1983). In addition, free member exit makes the cooperative face capital uncertainty and risks in the supply chain management (due to uncertain quantities).

In addition, redeeming net income, resulting from non-farmer related activities (e.g., many cooperative integrate into non-raw material related business) to the farmer- 
members through raw material prices, will distort market signals to the farmers. Producers will mistakenly interpret such incomes as a sign of increased demand for their products (Nilsson, 2001) and will tend to supply more raw materials (Royer, 1995). Finally, lack of transferability of residual claims on cooperative assets creates the horizon problem (Hendrikse \& Veerman, 1997; Nilsson, 1998; Vitaliano, 1983) that can affect the decision to invest in intangible assets such as research and development and marketing, which have very long or perpetual lives (Harte, 1997). Thus:

$\mathbf{H}_{2}$ : In comparison to re-engineered co-ops, ownership arrangements in traditional cooperatives will detract from (a) the market orientation and (b) the performance of the cooperative firm.

Finally, because cooperative members may have partially overlapping goals in a number of issues (e.g., allocation of overhead costs among different commodities, location of facilities) the traditional cost/profit allocation arrangements (equal prices and costs) can make nonfavored (often large) members exit the cooperative and pursue more attractive alternatives (Sexton, 1986; Staatz, 1984). This could leave the cooperative with less innovative farmers leading to production-oriented strategies. These problems could become more acute in cooperatives willing to engage in downstream and market-oriented activities as differences in membership become more pronounced. For example, when the Dutch fruit and vegetable growers' cooperative firm, The Greenery, expanded into the vertical chain, conflicts on how to distribute the accrued benefits evoked members' exit and upset the smooth supply to the retailers undermining the ambition of the cooperative firm to become market-oriented (Kyriakopoulos, 2000). Thus:

$\mathbf{H}_{3}$ : In comparison to re-engineered co-ops, cost allocation/pricing policies in traditional cooperatives will detract from (a) the market orientation and (b) the performance of the cooperative firm.

3.2.2 The effect of entrepreneurial cooperative firm culture. As discussed earlier, entrepreneurial cultures display four key attributes: risk-taking attitude, innovative leadership style, flexible bonding mechanisms, and proactive strategic emphasis (Moorman, 1995). These traits could improve market orientation and performance for several reasons. First, innovative leadership and risk-taking mentality help employees focus on how to position the firm vis à vis other market parties—satisfy customer needs, anticipate competitors' behavior, collaborate with supply chain partners - instead of catering to internal company needs, increasing, thus, the chances for superior customer value and superior performance (Deshpandé et al., 1993). Our argument, though applicable in many types of firms, carries special strength with respect to cooperatives. Given the dependence of the cooperative firm on members and their on-farm activities (Harte, 1997), innovative and risk-taking attitude is necessary to overcome this inherent internal, riskavoiding member orientation (Fulton, Fulton, Clark, \& Parliament, 1995).

Second, because organic structures have few authority lines and rules and more crossfunction integration (Burns \& Stalker, 1961), entrepreneurial cultures can be more adaptive and fast in planning and executing market activities (e.g., customer service, new product development, supply chain coordination), increasing the chances for success. Specifically, organic structure increases the cooperation among functions (e.g., marketing with $R \& D$ ), which is essential in reducing inefficiencies and offering integrating solu- 
tions to customers. Consistent with that, Jaworski \& Kohli (1993) found that interdepartmental connectedness improves while centralization hurts market orientation. Flexible, crossfunctional, and flat structures positively influence the innovativeness and performance of IOFs (Deshpandé et al., 1993), but it has particular importance for cooperatives. Because of their elaborate decision-making structure (farmers councils, farmers board, and management board), cooperatives are easy to get trapped in endless, political, and internal oriented discussions, hurting the quality and speed of decision-making (Henehan \& Anderson, 1994).

Third, because of their proactive strategies, entrepreneurial cultures will tend to anticipate competitive actions, spot latent customer needs, and monitor the environment for new trends, which improve market orientation (Moorman, 1995). In support, cooperatives engaged in offensive strategies (e.g., vertical and horizontal growth strategies) are more likely to adopt market orientation (Meulenberg, 1996; van Dijk et al., 1997). Thus:

$\mathbf{H}_{\mathbf{4}}$ : Entrepreneurial cooperative firm culture will add to (a) the market orientation and (b) performance of the cooperative firm.

\section{DATA COLLECTION AND MEASURES}

\subsection{Setting}

To test our hypotheses we study Dutch cooperative enterprises. They present a variety of organizational arrangements. Re-engineering that took place the last two decades has led to a diverse body of cooperatives including both traditional and re-engineered structural elements (van Dijk et al., 1997).

The sample of cooperatives was drawn from the list of member-cooperatives of NCR, the Dutch National Cooperative Council for Agriculture and Horticulture. This list in 1999 consisted of 62 cooperative firms, covering all agricultural cooperatives of importance. In fact, these cooperatives command substantial shares of the total business, both cooperative and private, of the respective Dutch agricultural sector. Heads of the cooperative affairs department were mailed a questionnaire and a letter to explain the purpose of the study and to request their participation. Due to the nature of their work (information and communication channel between members and the company), they are the most suitable persons to survey since they are knowledgeable about both the company and the members and are less biased in evaluating the outcome of the cooperative firm than the manager or the president of the board of directors as an interviewee.

The questionnaire consisted of two parts: the first one asked participants to describe the organizational arrangements with members while the second asked the participants to focus on marketing and general firm issues. The response rate is $85 \%$ yielding 52 questionnaires. Three cooperatives declined to cooperate, three were merged with other co-ops, and four did not return the questionnaires. The average turnover of the cooperative is 100 million EUR, ranging from 20 million to 4 billion EUR. 16 co-ops are supply, 29 are marketing, and 7 are both supply and marketing co-ops (for more information on the structural traits of the sample, see Table 1).

\subsection{Measurement}

4.2.1 Dependent variables. The study uses existing multi-item scales for measuring market orientation (Narver \& Slater, 1990) and performance (Deshpandé et al., 1993). 
Although there continues to be a debate about the measurement of market orientation (Deshpandé, 1999), we believe that the 7-point Likert scale developed by Narver \& Slater (1990) offers the most comprehensive view of market orientation that taps the competitor and customer orientation and interfunctional coordination inherent in a market orientation.

Performance is measured by a 5-point multi-item scale combining three indicators, profit margins, growth, and market share, all grounded in the PIMS study (Buzzell \& Gale, 1987) developed by Deshpandé et al. (1993). Given the difficulty of respondents in reporting absolute performance, we asked respondents to consider performance relative to their largest competitors, ensuring the same standard of comparison for all our respondents. To make the respondents' task easier and given our interest in cooperative firm outcomes, we asked them to focus on the cooperative firm and not the members' activities, when evaluating market orientation, culture, and firm performance.

4.2.2 Explanatory variables. For measuring entrepreneurial firm cultures, we rely on an existing multi-item 7-point Likert scale (Deshpandé et al., 1993). Given the four traits of culture, the scale relies on four items tapping the dominant attribute, leadership style of the cooperative firm, bonding, and strategic emphasis (see Appendix).

The three dimensions of cooperative structure are operationalized with questions to the respondents (directly related to the factors in Table 1), producing dummy variables $(1=$ re-engineered trait, $0=$ traditional trait). For measuring control, we relied on two questions related to (a) the voting principle (proportional, one member-one vote), and (b) the nonmember voting rights (yes, no). For measuring the ownership dimension, we used five questions related to (a) nonmember equity (yes, no), (b) proportional entry fees (yes, no), (c) individualized equity type (yes, no), (d) net income distribution (through stock dividend, through prices), and (e) equity redemption plans (yes, no). For measuring the cost/pricing policies, we asked two questions about (a) cost allocation (volumerelated, equal), and (b) pricing policy (quality-related, equal).

4.2.3 Control variable. We rely on a dummy variable to measure the structural variable, type of cooperative $(1=$ market cooperative, $0=$ supply cooperative $)$. We also control for the degree of competitive intensity in the major market of the cooperative firm by utilizing a multi-item scale (see Appendix) developed by Jaworski \& Kohli (1993).

\subsection{Variable Selection and Model-Testing Approach}

As indicated earlier, we use two types of variables: scale-measured and dummy variables. The scale-variables (i.e., market orientation, performance, culture, competitive intensity) are examined for reliability and unidimensionality ${ }^{6}$ (see Churchill, 1995) before we calculate the composite score of items for each variable. We assess reliability by calculating the Cronbach's alpha coefficient (Churchill, 1995). The criterion for reliability is above .65 for scales to adequately meet the standards for such research. All scales have greater

\footnotetext{
${ }^{6}$ This is necessary before the items in each scale are aggregated to measure the pertinent variable. Reliability refers to whether the various items of a scale belong to the domain of the variable (or share a common core) and it is measured by Cronbach alpha as a summary measure of the intercorrelations that exist among the items of a scale. Unidimensionality refers to the existence of a single trait underlying all the items of a scale and it is prerequisite for calculating a weighted sum of the items to provide an estimate of the scale. For example, 2 -factor solution for the four items of culture implies that culture has two dimensions, and no composite score can be computed from the four items as an estimate of culture.
} 
TABLE 2. Measure Characteristics

\begin{tabular}{lcccccccr}
\hline & Items & Range & Mean & \multicolumn{1}{c}{$S D$} & 1 & 2 & 3 & 4 \\
\hline (1) Entrepreneurial firm culture & 4 & $1-7$ & 4.33 & .92 & .70 & & & \\
(2) Market orientation & 13 & $1-7$ & 3.98 & .91 & $.38^{*}$ & .82 & & \\
(3) Performance & 3 & $1-5$ & 3.26 & 1.27 & $.24 * *$ & .11 & .70 & \\
(4) Competitive intensity & 4 & $1-7$ & 3.61 & .71 & -.09 & .03 & .05 & .77 \\
\hline
\end{tabular}

Note. The alpha associated with multi-item measures is on the diagonal in italics.

$* p<.05$. ** $p<.10$.

reliability alpha so they are retained in the analysis (firm culture $=.70$, market orientation $=.82$, competitive intensity $=.77$, performance $=.70$ ). Exploratory factor analysis is conducted to assess the unidimensionality of the scales, confirming that each scale's items were loaded on a single factor (low crossloadings and loadings $>.40$ ). Following this purification process and according to standard practice for multi-item scales (Churchill 1995), we compute the composite scores as an unweighted sum of the items of each scale to use them in the subsequent regression.

Turning to the dummy variables, some of them related to cooperative structure are not entered in the regression equation since they are highly correlated with other variables or because they do not display sufficient variation (see Table 1). Control is measured by the voting principle variable, as nonmember voting rights were adopted only by two co-ops. Ownership is measured by the existence of individualized equity since it is highly correlated (correlations between .41 and .58 , and significant at $p<.001$ ) to other variables associated with ownership (entry fees, equity redemption, dividend on members stock). This might be caused by the fact that cooperatives allocating equity to members often introduce high proportional entry fees, asset appreciation mechanisms, and pay dividend on member accounts as well. Nonmember equity is used by only four co-ops, and thus is not included in the analysis. Finally, because the variables measuring differentiated pricing and differentiated cost-allocation policy are highly correlated $(.49, p<.001)$, we decided to combine them into a new dummy variable $(1=$ cooperatives having either policy, $0=$ otherwise).

Because our final variables in the statistical model (e.g., individualized ownership) are somewhat different from the theoretical concepts (e.g., re-engineered ownership) used in the hypotheses, for reasons of clarity and precision, we will discuss our results in the context of the variables used in the regression analysis.

4.3.1 Model-testing approach The final linear regression models are as follows:

$$
\begin{aligned}
& Y_{1}=\alpha_{1}+\beta_{1} x+\gamma_{1} z+\delta_{1} w+\zeta_{1} v+\eta_{1} t+\theta_{1} s+\epsilon_{1} \\
& Y_{2}=\alpha_{2}+\beta_{2} x+\gamma_{2} z+\delta_{2} w+\zeta_{2} v+\eta_{2} t+\theta_{2} s+\epsilon_{2}
\end{aligned}
$$

where $Y_{1}=$ market orientation, $Y_{2}=$ performance, $x=$ voting, $z=$ ownership, $w=$ cost $/$ benefit allocation, $v=$ firm entrepreneurial culture, $t=$ competitive intensity, and $s=$ type of co-op, and $\epsilon_{1,2}=$ error $\approx\left(0, \sigma^{2}\right)$.

Having finalized the variables of the model, variance inflation factors were examined to check for multicollinearity and they were found to be below harmful levels (VIF < 10). 
TABLE 3. Standardized Estimates of the Hypothesized Relationships

\begin{tabular}{|c|c|c|}
\hline \multirow[b]{2}{*}{ Predictors } & \multicolumn{2}{|c|}{ Dependent variables } \\
\hline & Market orientation & Performance \\
\hline Proportional voting & $.17 \quad(1.15)$ & $-.35(-2.25) *$ \\
\hline Individualized ownership & $-.29(-1.63)$ & $.39 \quad(2.12)^{*}$ \\
\hline Differentiated cost/pricing policies & $.29 \quad(1.9) * *$ & $-.22(-1.38)$ \\
\hline Entrepreneurial firm culture & $.51 \quad(3.33) *$ & $.25 \quad(1.9)^{* *}$ \\
\hline Competitive intensity & $.01 \quad(.05)$ & $.14 \quad(.869)$ \\
\hline Type of co-op & $-.20(-1.28)$ & $-.11 \quad(.66)$ \\
\hline$F$-statistic (d.o.f) & $2.59 *(6,32)$ & $2.12 * *(6,34)$ \\
\hline Adjusted $R^{2}$ & .21 & .15 \\
\hline
\end{tabular}

Note. $t$-values in parentheses.

$* p<.05 . * * p<.10$.

\section{FINDINGS}

$\mathrm{H}_{1 \mathrm{a}}, \mathrm{H}_{2 \mathrm{a}}$, and $\mathrm{H}_{3 \mathrm{a}}$ predict that re-engineered control, ownership, and cost/pricing policies respectively would enhance market orientation. Results (see Table 3 ) show that the model overall is significant $\left(F_{(6,32)}=2.59, p<.05\right.$, adjusted $\left.R^{2}=.21\right)$. Proportional voting is positively but not significantly related to market orientation $(\beta=.17, t$-value $=1.15)$, failing to support hypotheses $\mathrm{H}_{1 \mathrm{a}}$, while individualized ownership has a negative and nonsignificant effect $(\beta=-.29, t$-value $=-1.63)$, failing also to support hypothesis $\mathrm{H}_{2 \mathrm{a}}$. Differentiated cost/pricing policies $(\beta=.29, t$-value $=1.9)$ have a significant effect; therefore, the hypothesis $\mathrm{H}_{3 \mathrm{a}}$ is supported. Finally, entrepreneurial culture has a significant effect on market orientation $(\beta=.51, t$-value $=3.33)$, supporting $\mathrm{H}_{4 \mathrm{a}}$.

Turning to the determinants of performance, $\mathrm{H}_{1 \mathrm{~b}}, \mathrm{H}_{2 \mathrm{~b}}$, and $\mathrm{H}_{3 \mathrm{~b}}$ theorize that the re-engineered control, ownership, and cost/pricing policies, respectively, would add to the performance of the cooperative firm. Overall, the results show that the regression model is significant $\left(F_{6,34}=2.12, p<.10\right.$, adjusted $\left.R^{2}=.15\right)$. The results indicate that proportional voting $(\beta=-.35, t$-value $=-2.25)$ has a significant but negative effect, failing to support $\mathrm{H}_{1 \mathrm{~b}}$. In contrast, individualized ownership has a positive and significant effect $(\beta=.39, t$-value $=2.12)$, supporting hypothesis $\mathrm{H}_{2 \mathrm{~b}}$. Differentiated cost $/$ pricing policies is found to be not significantly related to performance $(\beta=-.22, t$-value $=$ -1.38 ), failing to supports $\mathrm{H}_{3 \mathrm{~b}}$. Finally, entrepreneurial firm culture is found to have positive and significant effect $(\beta=.25, t$-value $=1.9)$, supporting $\mathrm{H}_{4 \mathrm{~b}}$ (Table 3$)$.

\section{DISCUSSION}

This study is an initial attempt to explore the relationship between organizational features of cooperatives and key outcomes of the cooperative firm. In this closing section, we consider the implications of our findings for cooperative theory as well as the study limitations and future research suggestions.

\subsection{Implications for Theory}

6.1.1 Main conclusion. Our research results offer limited support for the general thesis that structural cooperative features, summarized in the dichotomy traditional ver- 
sus re-engineered, systematically influence market orientation and performance of the cooperative firm. Some partial influences could be established and will be discussed below. However, it was found that entrepreneurial firm culture has a systematic influence on cooperatives' market orientation and performance. Our findings raise the question of whether the impact of cooperative structure has been over-emphasized in the literature. Our findings suggest that the quality of management and staff, and innovative and growthoriented values and attitude, typically present in entrepreneurial cultures, matter more than the choice of one or another cooperative structure. As a result, it is of paramount importance that cooperatives, whatever their structural features are, create conditions for the development of an entrepreneurial firm culture.

6.1.2 Specific conclusions. Some specific results bring to light interesting aspects of the impact of cooperative structure on performance and market orientation.

1. The effect of voting.

The results indicate that the variable voting has no effect on the market orientation and negative effect on performance. This might be due to the fact that equal voting rights is socially attractive, and so contributes to increase the number of members and thus adds to a large and cost-efficient production volume. For this to be economically beneficial, again a fairly homogeneous membership is required. Indeed, Albæk \& Schultz (1997) suggest that in a cooperative with many large farmers, the democratic voting rule leads to efficient investment decisions. Member homogeneity is probable in the Dutch case; for many decades, Dutch agricultural and Dutch agro-food industry has faced very intense competition, and this may have driven the agricultural production into becoming more homogeneous. These nuances suggest that democratic voting should be not dismissed as a relic of the past, but instead, it can still have an economic function in some circumstances.

2. The effect of ownership.

The negative but insignificant correlation between ownership and market orientation may relate to the type of market co-ops operate in (not examined in our study). Specifically, in commodity markets, individualized ownership could stimulate larger investments in product-oriented activities (e.g., acquiring co-ops/IOFs with similar commodity operations) rather than market orientation (e.g., new product development). The rationale is that co-ops, operating in the first stages of the vertical chain, can benefit from selling large volumes of standardized products at low prices, given large economies of scale (Nilsson, 1998). The results also indicate that among the three cooperative structural factors, individualized ownership enhances performance. This finding is in line with prior implicit and untested suggestions in the literature that the structure of property rights is instrumental in the cooperatives' ability to gather capital to invest in vertical activities (Royer, 1995).

3. The effect of cost/pricing policies.

The cooperative structural trait of differential cost/pricing policies clearly enhances market orientation. This finding is converging with previous findings about the importance of applying equitable treatment for a cooperative's stability and optimal production decisions in conditions of increasing member heterogeneity (Cobia \& Anderson, 1989; Sexton, 1986; Staatz, 1984;). In this way, the cooperative can stimulate big and entrepreneurial farmers to remain loyal to the cooperative, thereby reinforcing market orientation in two ways: supplying it with value-added products, 
as well as providing capital for investing in after-farm activities. Finally, the results indicate that a cost and pricing policy has an insignificant effect on performance. In theory, one would expect that differential cost and pricing policies are instrumental for the stability of the cooperative as cross-subsidies dwindle. If, however, membership is rather homogeneous, as we speculated earlier, equal pricing does not lead to cross-subsidies among farmer groups and, thus, does not mitigate the propensity of members to patron and finance their cooperative.

\subsection{Limitations and Future Research Suggestions}

While our results seem to contribute to a better understanding of cooperative strategies and management, there are some caveats associated with our measures and the model. First, despite the benefits of our performance measure (e.g., its broad scope by including profit margin, growth, market share), its self-reported nature might be a limitation. Concerns about biases are associated with social desirability and memory decay. One can argue, for example, that a certain group of respondents (e.g., re-engineered co-ops) tends to inflate performance. Future studies can benefit from combining self-reported measures and accounting-based measures (leverage, return on assets, liquidity, etc.), providing a robust picture of performance.

Second, apart from cooperative structural variables and entrepreneurial culture, other variables might influence market orientation and performance. To account for it, two more general variables - competitive intensity and type of co-op-have been included in our analysis. Their influence might represent the influence of other factors on market orientation and performance, e.g., the stage of the supply chain and the degree of product differentiation ${ }^{7}$ (Gruber, Rogers, \& Sexton, 2000). Future research could elaborate on the proposed model by including direct measures of the stage of food chain and the degree of product differentiation.

Third and related, these two variables (stage of food chain and the degree of product differentiation) are even more important for another reason: they provide a boundary condition for the effectiveness of a cooperative structure. Specifically, a cooperative structure can be suitable in a certain stage of the vertical chain and for a certain type of co-op. For example, the cooperative can choose to have a traditional structure, when operating in conditions of declining average cost and limited product differentiation (Nilsson, 1998). Adjusting cooperative structure to fit the market conditions or the type of cooperative raises issues of endogeneity (i.e., cooperative structure is no longer exogenous to the co-ops). Because our statistical model has not accounted for simultaneity related to structure, future research might take it into account. The same considerations apply to entrepreneurial culture because we cannot rule out a feedback from market orientation or performance to firm culture.

Finally, as we hinted earlier in the concluding section, the test of our hypotheses hinges on member heterogeneity being similar between the cooperatives. A traditional structure, however, might not pose serious problems when members do not differ substantially in farm size, or growing method, or investment preferences. Equal pricing, for example, might not be an issue when firms have similar cost structures. We have not accounted for such differences in member heterogeneity, an important variable that future research could measure in various ways. Accounting for differences in members' primary activities (e.g.,

\footnotetext{
${ }^{7} \mathrm{We}$ are thankful to one reviewer for providing this suggestion.
} 
farm size, value-added to the raw material on-farm, growing method) as well as their attitudes towards the cooperative firm (e.g., investment preferences in co-ops' processing activities) can advance empirical studies examining the impact of cooperative structure on the efficiency and effectiveness of the cooperative enterprise.

\section{APPENDIX}

\section{MEASURES}

Market orientation* (developed by Narver \& Slater, 1990)

1. Our salespeople regularly share information within our business concerning competitors' strategies.

2. Our business objectives are driven primarily by customer satisfaction.

3. We rapidly respond to competitive actions that threaten us.

4. We constantly monitor our level of commitment and orientation to serving customer needs.

5. Our top managers from every function regularly visit our current and prospective customers.

6. We freely communicate information about our successful and unsuccessful customer experiences across all business functions.

7. Our strategy for competitive advantage is based on our understanding of customers' needs.

8. All of our business functions (e.g., marketing/sales, manufacturing, R\&D, finance/ accounting, etc.) are integrated in serving the needs of our target markets.

9. We measure customer satisfaction systematically and frequently.

10. We give close attention to after-sales service.

11. Top management regularly discusses competitors' strengths and strategies.

12. All of our managers understand how everyone in our business can contribute to creating customer value.

13. We target markets where we have an opportunity for competitive advantage.

14. Customer orientation $(2,4,5,7,9,10)$, Competitor orientation $(1,3,11,13)$, Interfunctional coordination $(6,8,12)$.

Performance (developed by Deshpandé et al., 1993)

Relative to our business's largest competitors, we:

$$
\text { (1) }
$$

(a)

(b)

have much smaller profit margins

are growing much more slowly

(c)** have a much larger market share
(2)

have smaller profit margins

are growing more slowly

have a larger market share
(3)

have about equal profit margins are growing at about the same rate the same size about the same market share
(4)

(5)

have larger have significantly profit margins higher profit margins are growing are growing faster much faster

have a smaller have a much market share smaller market share 
Entrepreneurial Cooperative Firm Culture* (developed by Deshpandé et al., 1993)

My firm is very:

1. dynamic and entrepreneurial. People are willing to stick their necks out and take risks. (dominant attribute)

The head of my firm is generally considered to be:

2. an entrepreneur, an innovator, or a risk taker. (leadership style)

The glue that holds my firm together is:

3. a commitment to innovation and development. There is an emphasis on being first. (organizational bonding)

My firm emphasizes:

4. growth and acquiring new resources. Readiness to meet new challenges is important. (strategic emphasis)

Competitive intensity* (developed by Jaworski \& Kohli, 1993)

1. Competition in our industry is cutthroat.

2. There are many "promotion wars" in our industry.

3. Anything that one competitor can offer, others can match readily.

4. Price competition is a hallmark of our industry.

*Respondents were asked to fill in their response for each statement from culture, market orientation, and competitive intensity using a 7-point Likert scale where $1=$ "strongly disagree" and 7 = "strongly agree."

**Reverse-coded item. They are used to prevent a negative or positive respondent checking either the right or left hand side of the scale (Churchill, 1995).

\section{REFERENCES}

Albæk, S., \& Schultz, C. (1997). One cow, one vote. Scandinavian Journal of Economics, 99(4), 597-615.

Barton, D.G. (1989). Principles. In W.D. Cobia (Ed.), Cooperatives in agriculture (pp. 21-34). Englewood Cliffs, NJ: Prentice-Hall.

Burns, T., \& Stalker, G.M. (1961). The management of innovation. London: Tavistock.

Buzzell, R.D., \& Gale, B.T. (1987). The PIMS principles: Linking strategy to performance. New York: Free Press.

Cameron, K.S., \& Freeman, S.J. (1991). Cultural congruence, strength, and type: Relationships to effectiveness. In R.W. Woodman \& W.A. Passmore (Eds.), Research in organizational change and development (Vol. 5, pp. 23-58). Greenwich, CT: JAI Press.

Churchill, G.A., Jr. (1995). Marketing research: Methodological foundations (6th ed.). Chicago: The Dryden Press.

Cobia, W.D., \& Anderson, B.C. (1989). Product and pricing strategies. In W.D. Cobia (Ed.), Cooperatives in agriculture (pp. 174-194). Englewood Cliffs, NJ: Prentice-Hall.

Cobia, W.D., \& Brewer, T.A. (1989). Equity and debt. In W.D. Cobia (Ed.), Cooperatives in agriculture (pp. 243-266). Englewood Cliffs, NJ: Prentice-Hall.

Cook, M.L. (1994). The role of management behaviour in agricultural cooperatives. Journal of Agricultural Cooperation, 9, 42-58.

Cook, M.L. (1995). The future of US agricultural cooperatives: A neo-institutional approach. American Journal of Agricultural Economics, 77, 1153-1159.

Cook, M.L. (1997). Organisational structure and globalisation: The case of user oriented firms. In J. Nilsson \& G. Van Dijk (Eds.), Strategies and structures in the agro-food industries (pp. 77-93). Assen, NL: van Gorcum.

Deshpandé, R. (Ed.). (1999). Developing a market orientation. Thousand Oaks, CA: Sage. 
Deshpandé, R., Farley, J.U., \& Webster, Jr., F.E. (1993). Corporate culture, customer orientation, and innovativeness in Japanese firms: A quadrad analysis. Journal of Marketing, 57(1), 23-37.

Fulton, M., Fulton, J., Clark, J.S., \& Parliament, C. (1995). Cooperative growth: Is it constrained? Agribusiness, 11, 245-262.

Gentzoglanis, A. (1997). Economic and financial performance of cooperatives and investor-owned firms: An empirical study. In J. Nilsson \& G. Van Dijk (Eds.), Strategies and structures in the agro-food industries (pp. 171-182). Assen, NL: van Gorcum.

Ginder, R.G., \& Deiter, R.E. (1989). Managerial skills, functions and participants. In W.D. Cobia (Ed.), Cooperatives in agriculture (pp. 308-324). Englewood Cliffs, NJ: Prentice-Hall.

Gruber, J.L., Rogers, R.T., \& Sexton, R.J. (2000). Do agricultural marketing cooperatives advertise less intensively than investor-owned food processing firms. Journal of Cooperation, 15, $31-46$.

Hakelius, K. (1996). Cooperative values_-farmers' cooperatives in the minds of the farmers. Swedish University of Agricultural Sciences, Uppsala.

Harte, N.L. (1997). Creeping privatisation of Irish cooperatives: A transaction cost explanation. In J. Nilsson \& G. Van Dijk (Eds.), Strategies and structures in the agro-food industries (pp. 31-53). Assen, NL: van Gorcum.

Helmberger, P., \& Hoos, S. (1995). Cooperative enterprise and organisational theory. Journal of Cooperatives, 10, 72-86. (Reprinted from the Journal of Farm Economics, 44 (May 1963), 275-290.)

Hendrikse, G.W.J., \& Veerman, C.P. (1997). Marketing cooperatives as a system of attributes. In J. Nilsson \& G. Van Dijk (Eds.), Strategies and structures in the agro-food industries (pp. 111130). Assen, NL: van Gorcum.

Henehan, B.M., \& Anderson, B.L. (1994). Decision making in membership organizations: A study of fourteen U.S. cooperatives (A.R.M.E. Research Bulletin 94-5). Ithaca, NY: Cornell University.

Hind, A.M. (1994). Cooperatives-Underperformers by nature? An exploratory analysis of cooperative and non-cooperative companies in the agribusiness sector. Journal of Agricultural Economics, 45(2), 213-219.

Homburg, C., \& Pflesser, C. (2000). A multiple-layer model of market-oriented organizational culture: Measurement issues and performance outcomes. Journal of Marketing Research, 37(4), 449-462.

Jaworski, B.J., \& Kohli, A.K. (1993). Market orientation: Antecedents and consequences. Journal of Marketing, 57(3), 53-70.

Kyriakopoulos, K. (2000). The market orientation of cooperative organisations: Learning strategies and structures for integrating firms and members. Assen, NL: van Gorcum.

Lerman, Z., \& Parliament, C. (1990). Comparative performance of cooperatives and investorowned firms in US food industries. Agribusiness, 6, 527-540.

Meulenberg, M.T.G. (1996). Marketing organization, innovation and agricultural cooperatives. In G. Galizi \& L. Venturini (Eds.), Economics of innovation: The case of food industry (pp. 171186). Heidelberg: Physica-Verlag.

Moorman, C. (1995). Organizational market information processes: Cultural antecedents and new product outcomes. Journal of Marketing Research, 32(3), 318-335.

Narver, J.C., \& Slater, S.F. (1990). The effect of a market orientation on business profitability. Journal of Marketing, 20(4), 20-35.

Nilsson, J. (1998). The emergence of new organizational models for agricultural cooperatives. Swedish Journal of Agricultural Research, 28, 39-47.

Nilsson, J. (2001). Organizational principles for cooperative firms. Scandinavian Journal of Management, 17, 329-356.

Nourse, E.G. (1945). The place of the cooperative in our national economy. In American Cooperation 1942-1945 (pp. 33-39). Washington, DC: American Institute of Cooperation.

Porter, M.E. (1980). Competitive strategy: Techniques for analysing industries and competitors. New York: The Free Press.

Quinn, R.E. (1988). Beyond rational management. San Francisco: Jossey-Bass.

Quinn, R.E., \& McGrath, M.R. (1984). The transformation of organizational cultures: A competing values perspective. In P.J. Frost, M.R. Louis, C.C. Lundberg, L.F. Moore, \& J. Martin (Eds.), Organizational culture. Beverly Hills, CA: Sage.

Quinn, R.E., \& Rohrbaugh, J. (1983). A spatial model of effectiveness criteria: Toward a competing values approach to organizational analysis. Management Science, 29(3), 363-77. 
Royer, J.S. (1995). Potential for cooperative involvement in vertical co-ordination and value-added activities. Agribusiness, 11, 473-481.

Sexton, R.J. (1986). The formation of cooperatives: A game-theoretic approach with implications for cooperative finance, decision making, and stability. American Journal of Agricultural Economics, 68, 214-225.

Sexton, R.J., \& Iskow, J. (1988). Factors critical to the success or failure of emerging agricultural cooperatives (Gianini Foundation Information Series No. 88-3). Davis, CA: University of California.

Staatz, J.M. (1983). The cooperative as a coalition: A game-theoretic approach. American Journal of Agricultural Economics, 65, 1084-1089.

Staatz, J.M. (1984). A theoretical perspective on the behaviour of farmers' cooperatives. Unpublished doctoral dissertation, Michigan State University.

Van Dijk, G., Kyriakopoulos, K., \& Nilsson, J. (1997). Overview and Discussion-The future of agricultural cooperatives in the EU. In O.F. van Bekkum \& G. Van Dijk (Eds.), The development of agricultural cooperatives in the European Union (pp. 167-193). Assen, NL: van Gorcum.

Van Dijk, G., \& Mackel, C. (1991). Dutch agriculture seeking for market leader strategies. European Review of Agricultural Economics, 18, 345-364.

Vitaliano, P. (1983). Cooperative enterprise: Alternative conceptual basis for analysing a complex institution. American Journal of Agricultural Economics, 65, 1078-1083.

Kyriakos Kyriakopoulos is an Assistant Professor at the University of Maastricht, Department of Marketing, the Netherlands. He earned his PhD in Marketing and Cooperatives in 2000 from the Nyenrode University, the Netherlands, an MSc in Agricultural Economics and Food Marketing from Wageningen University, the Netherlands, and in Agronomy from Agricultural University of Athens, Greece. His current research interests are market learning, new product development, strategic marketing, and cooperatives' marketing strategy.

Matthew Meulenberg is a Professor Emeritus of Marketing at Wageningen University. He obtained an MSc in Horticultural Science in 1957 and a PhD in Agricultural Economics in 1962, both from Wageningen University, the Netherlands. His current research interests include topics in the field of distribution, marketing channels, and consumer behavior.

Jerker Nilsson is a Professor of Cooperative Business and Marketing, Department of Economics, at the Swedish University of Agricultural Sciences. He earned his PhD in Economics in 1980 from Lund University, Sweden. His current research interests are structural change in the agrofood systems, organizational models for agricultural cooperatives, and marketing strategies for agrofood products. 